\title{
A social work study on the effect of emotional intelligence factors on recovering people addicted to drugs
}

\author{
Seyed Esmael Mosavi ${ }^{a^{*}}$, Mohammad Reza Iravani ${ }^{b}$, Asghar Nikbakht ${ }^{c}$, Ebrahim Yazdi ${ }^{d}$ and Amin \\ Movahedie $^{e}$
}

${ }^{a}$ Counseling department, Islamic Azad University of Khomeinishahr, Khomeinishahr Branch, Daneshjou Blvd, Iran

${ }^{b}$ Department of Social Work, Islamic Azad University of Khomeinishahr, Khomeinishahr Branch, Daneshjou Blvd, Iran

${ }^{c}$ Department of Economic, Khomeinishar Branch, Islamic Azad University, Isfahan ,Iran

${ }^{d}$ Master of Educational Administration, Iran

${ }^{e}$ Master of Social Work, Iran

\section{A R T I C L E I N F O}

\section{Article history:}

Received March 10, 2012

Received in Revised form

July, 12, 2012

Accepted 5 August 2012

Available online

10 August 2012

Keywords:

Emotional intelligence

Social work study

Drug addiction

Drug addiction recovery

\begin{abstract}
A B S T R A C T
Drug addiction has become serious problem in many developing countries. Many young people are addicted to different toxicated materials and, as a result, they cannot contribute to their societies. They lose any employment opportunity, cannot continue their education and lose their healthcare. This paper considers the effect of emotional intelligence (EQ) and the likelihood of recovery among addicted people who were under recovery treatments in three different groups in city of Esfahan, Iran including community-based treatment (CT) group, no support addictives (NA) and recovery center. The proposed study uses two types of questionnaires including 90 questions with 15 scales. The survey also uses a standard questionnaire to determine the likelihood of return to drug. The survey uses three samples of people from each three-drug recovery centers. In this study, we perform regression analysis and our survey results show that return to drug is inversely related with being realistic $(-2.618)$, optimism $(-2.409)$ and locus of control (-2.094).
\end{abstract}

C) 2012 Growing Science Ltd. All rights reserved.

\section{Introduction}

Addiction is one of the most important issues threatening young people in developing countries specially those who live in Middle East countries. Unfortunately, there are countries who are victims of drug solely because of geographical position they have and there is a strong need to perform social studies to find the effects of different issues on addiction. One of the primary issues in such studies is to learn the effect of emotional intelligence (EI) on drug addiction. During the past few decades, there are enormous studies on this kind of investigation (Matthews et al., 2006; Williams et al., 2009; de Sousa Uva et al., 2010; Côté et al., 2010.; Kilduff et al., 2010; Joseph \& Newman, 2010; Schutte \& Malouff, 2011). Besharat (2007) presented psychometric properties of Farsi version of the EI Scale41.

* Corresponding author. Tel.: +989131062110

E-mail addresses: es.mosavi@iaukhsh.ac.ir (S. E. Mosavi) 
La Salvia (1993) performed an investigation on enhancement of addiction treatment through psychoeducational groups. Based on this survey, addicted people were strongly suffered from their own personalities and self-confidence and it was believed that these issues could be treated through a continuous treatment. In addition, a psychoeducational group in the treatment of addictions served as a synthesis for problem-solving skills training implemented in mental health and the psychodynamic theory of addictive behavior. They also presented some cases to illustrate the efficacy of psychoeducational groups.

Naisberg (2002) reported that there was a meaningful relationship between an increase awareness on drug consequences and reduction on anti-drug attitudes. The survey also reported that it is quite possible to reduce drug addiction by reducing stress. Rohsenow et al. (2000) performed a survey among 108 people who received medication to recover from drug addiction usage for a period of three months and six months later, the investigation indicated positive results against drug usage.

Weaver et al. (2000) performed another investigation on depressive symptoms, stress, and coping among women recovering from addiction. They performed an investigation among 103 people who tried to get rid of drug addiction for a ten-year period and realized that stress was reduced among them to recover them from disease. Pelliteri (1999) performed an investigation on the relationship between emotional intelligence, cognitive reasoning, and defiance mechanism.

Kissin et al. (2003) performed an investigation on the longitudinal relationship between self-help group attendance and course of recovery. They discussed that most alcohol and other drug (AOD) abuse patients participated in self-help ( $\mathrm{SH}$ ) programs such as Alcoholics Anonymous or Narcotics Anonymous at some time. They examined the relationship between longitudinal SH attendance patterns and level of AOD use over 30 months in a large sample of adults seeking public AOD treatment. They reported that both $\mathrm{SH}$ and formal substance abuse treatment were independently related to reduced AOD use, and SH participation was associated with treatment.

Song et al. (2010) investigated the differential effects of general mental ability and emotional intelligence on academic performance and social interactions. They considered the debate on whether EI had incremental validity over and above traditional intelligence dimensions and proposed that EI and general mental abilities (GMA) differ in predicting academic performance and the quality of social interactions among college students. Using two university student samples, they reported some support for the notion that EI and GMA each had a unique power to predict academic performance, and that GMA was the stronger predictor.

Trinidad and Johnson (2002) investigated the relationship between emotional intelligence and early addiction in tobacco and alcohol. They reported that the adolescents with high EI could possess a greater mental ability to read others well and detect unwanted peer pressure.

Khanmohammadi et al. (2009) reported that applying of some plans in the field of increasing EI could help people with positive attitudes to addiction to manage the bad problems and event and as a result reduce tendency to addiction. Talebzadeh and Homayouni (2010) performed a survey on relationship between emotional intelligence and personality traits in addicted people. The results of their survey indicated that high emotional intelligence was related positive and significant with extroversion, openness to experience and conscientiousness. They also recommended to set the programs for enhancing the EI to increase mental health, life satisfaction and social skills to have personality and psychological health and prevent tendency to abnormal behavior specially tendency to addiction.

Hill and Maggi (2011) investigated the relationship between EI and drug addiction among Canadian youth. They measured emotional intelligence with a short-form of the original EQ-i (), which evaluated overall emotional intelligence and five dimensions: interpersonal competencies, intrapersonal competencies, stress management competencies, adaptability competencies and general mood. They divided their participants into three groups of daily, occasional or non-smokers and 
performed multinomial logistic regression analyses to examine the association between emotional intelligence with daily and occasional smoking. Their results suggested that emotional intelligence could comprise gender-specific protective and risk factors for occasional and daily smoking, which in turn is in the development of smoking prevention programs. There are also new generations of drug addiction such as addiction to internet, playing games, talking with mobile phones, etc.

Beranuy et al. (2009) investigated internet and mobile phone addiction and clinical symptoms in college students by investigating EI effects. Parker et al. (2008) studied the relationship between EI among those people who aggressively use internet or mobile services. Khatiri Yanesari et al. (2010) investigated whether EI could prevent addiction to internet. They showed that there was negative significant correlation between components of EI including appraisal of emotion, utilization of emotion and general score of emotional intelligence. They reported that higher levels of emotional intelligence associated with lower levels of addiction to internet.

The proposed study of this paper investigates the impact of EI on different groups addicted to drugs using some statistical methods. This work is also associated with the previous study held by Iravani and Mosavi (2012), where they measured emotional intelligence among different groups of people who were addicted to drugs. In their recent study, they distributed a questionnaire among three groups consists of 117 questions and 15 scales. The first group of the survey was under community-based treatment, the second group included people who were members of a community with unknown identifications, and the third group covers outpatient patient who receive medication. The results of their survey indicated that the level of emotional intelligence among the first group of our study was much more than the other groups.

The organization of this paper first explains details of our study in section 2 . Section 3 is devoted to the results of our survey. Finally, concluding remarks are given in the last to summarize the contribution of the paper.

\section{Problem statement}

The proposed study of this paper has adopted standard EI questionnaire which was examined on 3831 people from 6 different nationalities and the results was believed to be valid. We have examined the results through three levels of verification tests. In the first level, we consulted details of our questions with some experts and received their opinions. In the second run, we performed some preliminary tests on the questionnaire and after some validation test; the questionnaires were distributed among people who participated in our survey. We have chosen three groups with equal size of 50 people from each group. The proposed study uses the following regression analysis,

$$
Y_{i}=\beta_{0}+\beta_{1} X_{1 i}+\beta_{2} X_{2 i}+\beta_{3} X_{3 i}+\varepsilon_{i},
$$

where $X_{1 i}, X_{2 i}$ and $X_{3 i}$ represent being realistic, optimism and locus of control, $\beta_{0}, \beta_{1}$ and $\beta_{2}$ are coefficients and $\varepsilon$ is the residual, respectively. The dependent variable $Y_{i}$ represents the likelihood of returning a patient to drug. As we can observe from Eq. (1), the proposed study uses simple linear regression to analysis the relationship. In order to use ordinary least square (OLS) we need to verify the normality test first.

Fig. 1 shows the results of Kolmogrov Smirnov (KS) test on NA. As we can see from the test results, data are normally distributed. Similar observations hold for other variables. The other test is to understand whether there is any correlation between residuals and we can investigate it by looking at the residuals' graph shown in Fig. 2. As we can observe, there is no pattern between residuals and we can conclude that there is no autocorrelations between residuals. 


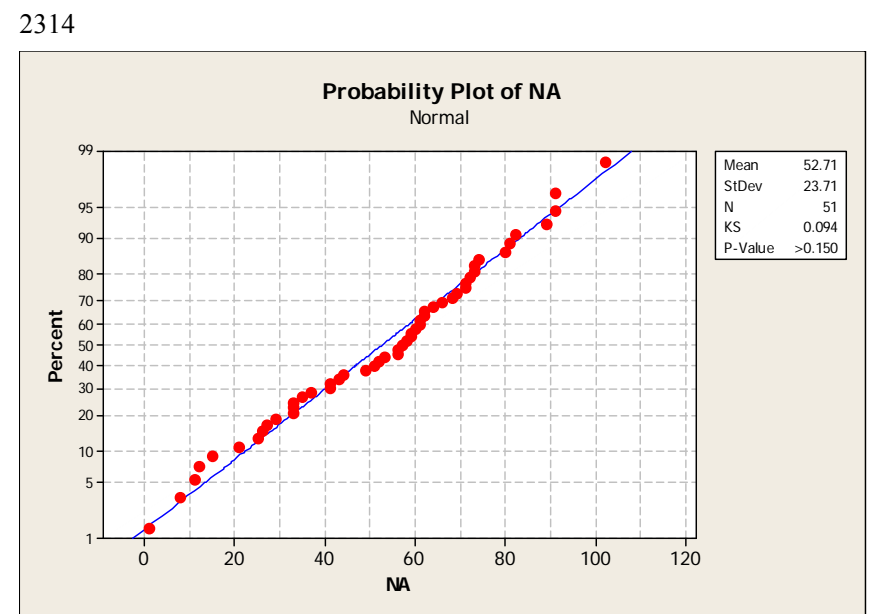

Fig. 1. The results of normality test

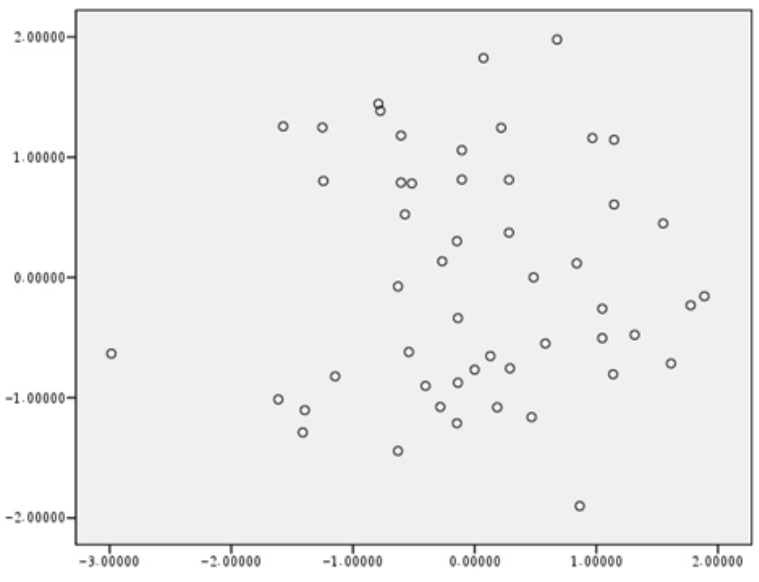

Fig. 2. The plot of residuals $u_{i}$ and $u_{j}$

\section{The results}

In this section, we present the results of our regression analysis using stepwise method. Table 1 shows the results of our investigation.

Table 1

The results of stepwise regression analysis

\begin{tabular}{ccccccccc}
\hline & \multicolumn{9}{c}{$\begin{array}{c}\text { Unstandardized } \\
\text { coefficients }\end{array}$} & $\begin{array}{c}\text { Standardized } \\
\text { coefficients }\end{array}$ & & & \multicolumn{2}{c}{$\begin{array}{c}\text { Collinearity } \\
\text { statistics }\end{array}$} \\
\hline Step & Variable & $\beta$ & Std. Error & $\beta$ & t-student & Sig. & Tolerance & VIF \\
\hline 1 & $\beta_{0}$ & 103.163 & 17.757 & & 5.810 & 0.000 & & \\
& $\beta_{1}$ & -3.104 & 1.076 & -0.381 & -2.886 & 0.006 & 1.000 & 1.000 \\
\hline & $\beta_{0}$ & 119.478 & 18.577 & & 6.431 & 0.000 & & \\
2 & $\beta_{1}$ & -2.501 & 1.069 & -0.307 & -2.340 & 0.024 & 0.936 & 1.068 \\
& $\beta_{2}$ & -1.776 & 0.796 & -0.293 & -2.231 & 0.030 & 0.936 & 1.068 \\
\hline & $\beta_{0}$ & 172.293 & 29.694 & & 5.802 & 0.000 & & \\
& $\beta_{1}$ & -2.618 & 1.029 & -0.321 & -2.544 & 0.014 & 0.934 & 1.071 \\
3 & $\beta_{2}$ & -2.094 & 0.778 & -0.345 & -2.691 & 0.010 & 0.905 & 1.106 \\
& $\beta_{3}$ & -2.409 & 1.082 & -0.278 & -2.226 & 0.031 & 0.957 & 1.045 \\
\hline
\end{tabular}

As we can observe from the results of stepwise regression analysis, all three variables along with constant number are statistically meaningful when the level of significance is five percent. T-student values are statistically significant. We have also performed ANOVA test to see whether the whole model is valid, which yields $F$-value $=12.266$ with $P$-value $=0.000$. This means the null hypothesis can be rejected and we can accept the resulted regression for our observation. In summary the regression analysis is stated as follows,

$$
\begin{aligned}
& \qquad Y_{i}=172.293-2.618 X_{1 i}-2.094 X_{2 i}-2.409 X_{3 i}+\varepsilon_{i}, \\
& \text { t-value }(5.802) \quad(-2.544) \\
& \text { F-value }=12.226
\end{aligned}
$$

According to the results of regression analysis, when a person gets rid of addiction, there will be less chance of returning to drug as he/she becomes more realistic, preserves more optimism in the world and maintains more locus of control. In other words, it is possible to reduce drug addiction by increasing societies' emotional intelligence components. In fact, it seems that a society with more sense of optimism will less likely go on drug and social media could play an important role on 
preventing from drugs and once people go under medication, treatment must include improvement on locus of control, increases optimism among patients and improves locus of control.

\section{Conclusion}

In this paper, we have presented an empirical study to measure emotional intelligence among different groups of people who were addicted to drugs. Drug addiction has become serious problem among many developing countries. Many young people become addicted to different toxicated materials and, as a result, they cannot contribute to their society. They lose any employment opportunity, cannot continue their education and lose their healthcare. This paper considers the effect of emotional intelligence (EQ) and the likelihood of recovery among addicted people who were in three different groups in city of Esfahan, Iran including community-based treatment (CT) group, no support addictives (NA) and recovery center. The proposed study uses two types of questionnaires including 90 questions with 15 scales. The survey also uses a standard questionnaire to determine the likelihood of return to drug. The survey used three samples of people from each three-drug recovery centers. In this study, we perform regression analysis and our survey results show that return to drug is inversely related with being realistic (-2.618), optimism (-2.409) and locus of control (-2.094).

According to the results of regression analysis, when a person gets rid of addiction, there will be less chance of returning to drug as he/she becomes more realistic, preserves more optimism in the world and maintains more locus of control. In other words, it is possible to reduce drug addiction by increasing societies' emotional intelligence components. In fact, it seems that a society with more sense of optimism will less likely go on drug and social media could play an important role on preventing from drugs and once people go under medication, treatment must include improvement on locus of control, increases optimism among patients and improves locus of control.

\section{Acknowledgment}

The author would like to thank Islamic Azad University for their financial support on this project. The author also grateful for constructive comments received from the anonymous referees on earlier version of this working paper.

\section{References}

Besharat, M.A. (2007). Psychometric properties of Farsi version of the Emotional Intelligence Scale41 (FEIS-41). Personality and Individual Differences, 43(5), 991-1000.

Beranuy, M., Oberst, U., Carbonell, X., Chamarro, A. (2009).Problematic Internet and mobile phone use and clinical symptoms in college students: The role of emotional intelligence. Computers in Human Behavior, 25(5), 1182-1187.

Côté, S., Lopes, P.N., Salovey, P., \& Miners, C.T.H. (2010). Emotional intelligence and leadership emergence in small groups. The Leadership Quarterly, 21(3), 496-508.

Hill, E.M., \& Maggi, S. (2011). Emotional intelligence and smoking: Protective and risk factors among Canadian young adults. Personality and Individual Differences, 51(1), 45-50.

Hochberg, Y., \& Tamhane, A.C. (1987). Multiple Comparison Procedures. John Wiley \& Sons.

Iravani, M.R., \& Mosavi, S.E. (2012). A social work study on emotional intelligence among different groups of people how are addicted to drugs. Management Science Letters, 2(1), 119-124.

Joseph, D.L., Newman, D.A. (2010). Emotional Intelligence: An Integrative Meta-Analysis and Cascading Model. Journal of Applied Psychology, 95(1), 54-78.

Kissin, W., McLeod, C., \& McKay, J. (2003). The longitudinal relationship between self-help group attendance and course of recovery. Evaluation and Program Planning, 26(3), 311-323

Khanmohammadi, A., Homayouni, A., Mosavi Amiri, S.J., \& Nikpour, G.A. (2009). P01-43 Low emotional intelligence as a predictor of tendency to addiction. European Psychiatry, 24, S431. 
Khatiri Yanesari, M., \& Homayouni, A., \& Gharib, K. (2010). P02-99 - Can emotional intelligence predicts addiction to internet in university students? European Psychiatry, 25(1), 748.

Kilduff, M., Chiaburu, D.S., \& Menges, J.I. (2010). Strategic use of emotional intelligence in organizational settings: Exploring the dark side. Research in Organizational Behavior, 30, 129152.

La Salvia, T. (1993). Enhancing addiction treatment through psychoeducational groups. Journal of Substance Abuse Treatment, 10(5), 439-444.

Lopes, R.H.C., Reid, I., \& Hobson, P.R. (2007). The two-dimensional Kolmogorov-Smirnov test. XI International Workshop on Advanced Computing and Analysis Techniques in Physics Research (April 23-27, 2007) Amsterdam, the Netherlands.

Matthews, G., Emo, A.K., Funke, G., Zeidner, M., Roberts, R.D., Costa Jr., P.T., \& Schulze, R. (2006). Emotional Intelligence, Personality, and Task-Induced Stress. Journal of Experimental Psychology: Applied, 12(2), 96-107.

Naisberg, Y. (2002). Long-term biophysical synchronization for pretention of addiction spectrum for nation in high risk children and adolescents. theory and practice hypotheses. Journal of consulting and clinical psychology, 58, 433-439.

Parker, J.D.A., Taylor, R.N., Eastabrook, J.M., Schell, S.L., \& Wood, L.M. (2008). Problem gambling in adolescence: Relationships with internet misuse, gaming abuse and emotional intelligence. Personality and Individual Differences, 45(2), 174-180.

Pelliteri, J. (1999). The relationship between emotional intelligence, cognitive reasoning, and defiance mechanism. Journal of consulting and clinical psychology, 27(2), 113-122.

Rohsenow, D., Monti, P., Martin, R., Michalec, E., \& Abrams, D. (2000). Brief coping skills treatment for cocaine abuse: 12-month substance use outcomes. Journal of Consulting and Clinical Psychology, 68(3), 515-520.

Schutte, N.S., \& Malouff, J.M. (2011).Emotional intelligence mediates the relationship between mindfulness and subjective well-being. Personality and Individual Differences, 50(7), 1116-1119.

de Sousa Uva, M.C., de Timary, P., Cortesi, M., Mikolajczak, M., du Roy de Blicquy, P., Luminet, O. (2010). Moderating effect of emotional intelligence on the role of negative affect in the motivation to drink in alcohol-dependent subjects undergoing protracted withdrawal. Personality and Individual Differences, 48(1), 16-21.

Song, L.J., Huang, G.H., Peng, K.Z., Law, K.S., Wong, C.S., \& Chen, Z. (2010). The differential effects of general mental ability and emotional intelligence on academic performance and social interactions. Intelligence, 36(1), 137-143.

Talebzadeh Sani, H., \& Homayouni, A. (2010). P03-262 - A survey on relationship between emotional intelligence and personality traits in addicted people. European Psychiatry, 25(1), 1329.

Trinidad, D.R., \& Johnson, C.A. (2002). The association between emotional intelligence and early adolescent tobacco and alcohol use. Personality and Individual Differences, 32(1), 95-105.

Weaver, G., Turner, N.H., \& O'Dell, K. (2000). Depressive symptoms, stress, and coping among women recovering from addiction. Journal of Substance Abuse Treatment, 18(2), 161-167.

Williams, C., Daley, D., Burnside, E., \& Hammond-Rowley, S. (2009). Measuring emotional intelligence in preadolescence. Personality and Individual Differences, 47(4), 316-320. 